\title{
'HENDERSON'S' RELIEF OF EYELID RETRACTION REVISITED
}

\author{
JANE M. OLVER and PETER FELLS \\ London
}

\begin{abstract}
SUMMARY
The purpose of the study was to identify those patients with thyroid eye disease and upper eyelid retraction who would benefit from Henderson's procedure (myotomy of Muller's superior tarsal muscle with graded division of levator aponeurotic fibres on the anterior tarsal plate). The clinical records of patients attending the Thyroid Clinic of Moorfields Hospital who had undergone Henderson's procedures were reviewed. Twenty-two patients (19 women, 3 men) had Henderson's procedures at age 35-69 years (mean 49.9), with a mean follow-up of 4.55 years. Eleven patients had biateral upper eyelid surgery, 11 unilateral (33 eyelids). The pre-operative vertical palpebral apertures ranged from 11 to $19 \mathrm{~mm}$ (mean 13.95); the post-operative vertical palpebral apertures ranged from 8 to $15 \mathrm{~mm}$ (mean 11.45), a mean reduction of $2.5 \mathrm{~mm}(p<0.001)$. Eight of twenty-two patients $(36 \%)$ had further eyelid surgery and 3 of 22 (14\%) had further surgery recommended because of persistent upper eyelid retraction, abnormal eyelid contour (lateral flare) and asymmetry. It is concluded that Henderson's procedure should be reserved for those patients with minor degrees of almost symmetrical upper eyelid retraction who do not have abnormalities of their eyelid contour.
\end{abstract}

Eyelid retraction occurs frequently in thyroid eye disease, ${ }^{1,2}$ producing a typical staring facies which patients find both embarrassing and socially disabling. Upper eyelid retraction is primarily due to thickening and shortening of the levator muscle and is also related to the degree of associated proptosis. ${ }^{3,4}$ Over-action of Muller's muscle can result in a variable degree of upper eyelid retraction. Tight inferior recti causing limited upgaze can result in secondary upper eyelid retraction. ${ }^{5}$ Lateral contour flare or temporal flare of the upper eyelid commonly occurs in association with retraction.

Many surgical procedures are available to lengthen the upper eyelid retractors in patients with thyroid

Correspondence to: Jane Olver, Western Ophthalmic Hospital, Marylebone Road, London NW1 5YE, UK. eye disease. These include several in which the levator aponeurosis or muscle is divided, ${ }^{6-8}$ mullerotomy, ${ }^{9}$ mullerectomy with or without levator recession, ${ }^{10-13}$ insertion of a scleral graft spacer, ${ }^{14}$ levator marginal myotomy ${ }^{15,16}$ and levator recession on adjustable sutures. ${ }^{17}$

The choice of operation depends on both the degree of upper eyelid retraction and the oculoplastic experience of the surgeon. In 1965 Henderson described his procedure for eyelid retraction. This consisted of mullerotomy via a posterior (conjunctival) approach with graded division of the levator aponeurotic fibres on the anterior surface of the tarsal plate (Fig. 1). The main advantages of this procedure are said to be that it does not overcorrect the eyelid retraction and that the superior palpebral fold does not rise. This is based on the experience of 27 operations (47 upper eyelids) performed by Henderson between 1957 and 1963. Henderson's procedure is still in common clinical use because it is quick, it employs no sutures and the anatomy of the operation is simple. The aim of this review is to identify for which patients Henderson's procedure is most appropriate.

\section{METHODS}

The hospital records of all patients from the Thyroid Clinic at Moorfields Eye Hospital who had undergone correction of upper eyelid retraction by Henderson's procedure were reviewed. Details recorded included the indications for surgery, previous surgery, measurements of proptosis, upper eyelid retraction and the vertical palpebral apertures, the duration of follow-up after surgery and details of further surgery. The results were analysed was using Oxstat II (version 1.11 Microsoft, Seattle) and Fig P (version 6.0 Biosoft, Cambridge).

\section{RESULTS}

The hospital notes of 22 patients ( 19 women, 3 men) were reviewed. These patients had Henderson's 


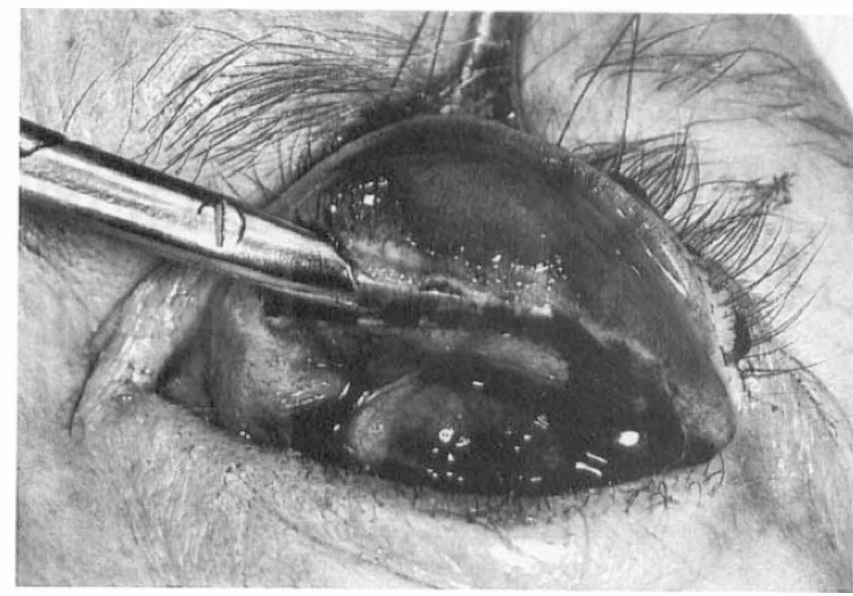

(a)

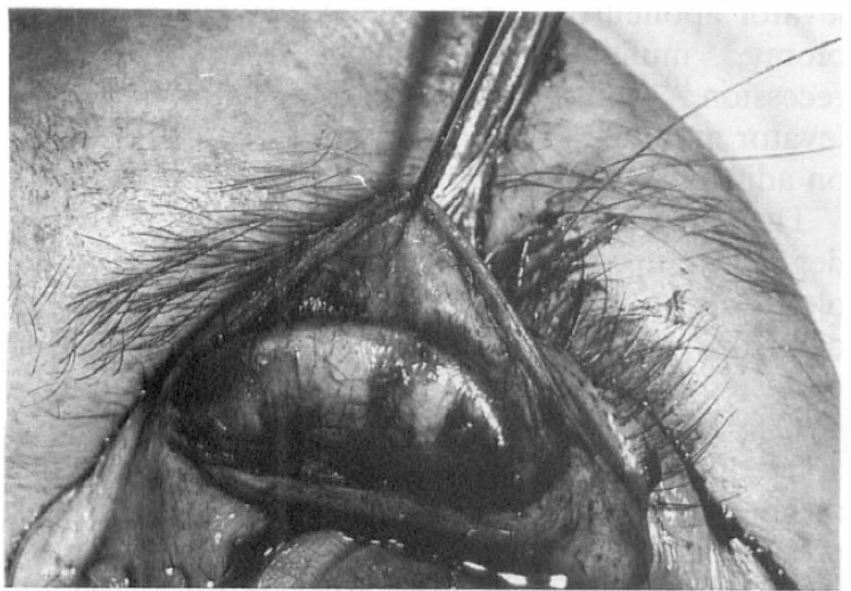

(c)

procedures performed between the ages of 35 and 69 years (mean 49.9, median 49.5). None had undergone previous upper eyelid surgery. Follow-up ranged from 0.5 to 20 years (mean 4.55, median 3). Details of the presenting endocrine status were known in 17 of 22 patients (hyperthyroid); there were no details recorded in 5 of 22 patients. Onset of hyperthyroidism occurred between the ages of 18 and 63 years (mean 44.59, median 46). The age at which the patient first noticed signs of thyroid eye disease was known for all patients and ranged from 18 to 63 years (mean 44.86, median 45.5). The duration of the thyroid eye disease before undergoing eyelid surgery ranged from 1 to 30 years (mean 5, median 3 ).

Two patients had undergone previous orbital decompressions and subsequent strabismus surgery; 6 patients had had previous strabismus surgery only. Fourteen patients had had no previous orbital or strabismus surgery at all. The indications for surgery were mainly cosmetic. Eight patients also had lagophthalmos. A unilateral Henderson's procedure was performed in 11 patients and bilateral Henderson's procedures in 11 patients. In total, therefore, operations were carried out on 33 upper eyelids.

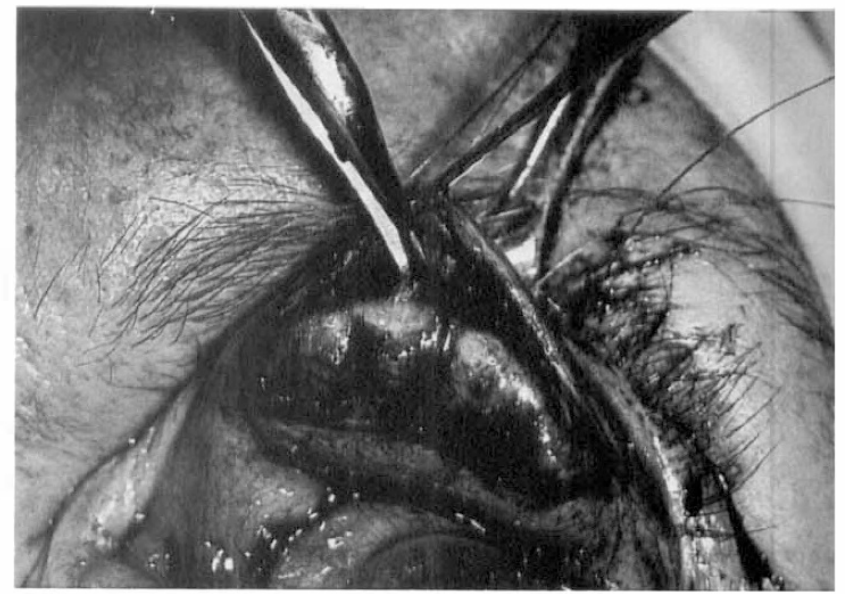

(b)

Fig. 1. Per-operative left upper lid Henderson's procedure. The upper eyelid is everted over a Desmarres retractor. (a) The conjunctiva has been opened at the upper border of the tarsal plate. Westcott scissors are in the post-aponeurotic space with Muller's muscle overlying them. (b) The upper border of the tarsal plate is being held in order for the levator aponeurotic fibres on the anterior surface of the tarsal plate to be divided. (c) The aponeurotic fibres on the anterior tarsal surface have been divided.

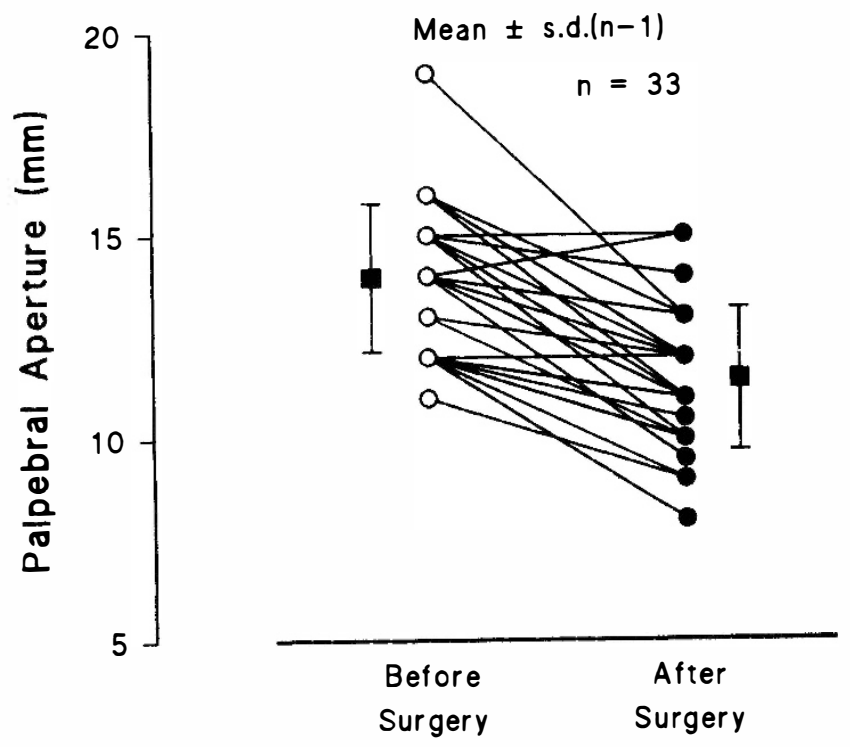

Fig. 2. The change in vertical palpebral aperture following Henderson's procedure is shown for 33 upper eyelids. Preoperatively the palpebral aperture range was 11-19 $\mathrm{mm}$ (mean 13.95); post-operatively this was reduced to $8-15 \mathrm{~mm}$ (mean 11.45), a mean reduction of $2.5 \mathrm{~mm}$ ( $\mathrm{p}<0.001$, paired $\mathrm{t}$-test). 


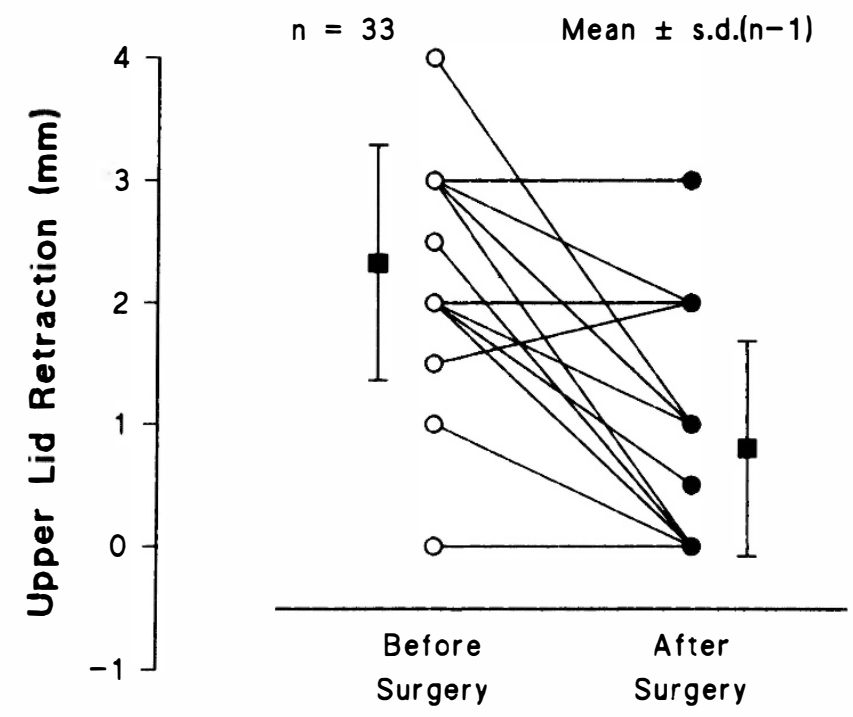

Fig. 3. The change in upper eyelid retraction (upper scleral show) following Henderson's procedure is shown for 33 upper eyelids. Pre-operatively the range of upper eyelid retraction (upper scleral show) was 0-4 $\mathrm{mm}$ (mean 2.3); post-operatively this was reduced to 0-3 $\mathrm{mm}$ (mean 0.8), a mean reduction of $1.5 \mathrm{~mm}(\mathrm{p}<0.001$, paired $\mathrm{t}-$ test $)$.

The amounts of upper eyelid lowering achieved are shown in Figs. 2 and 3, based on reduction of vertical palpebral aperture and reduction of upper eyelid retraction (upper scleral show) measurements. The difference between the pre-operative and postoperative measurements for both palpebral aperture and upper eyelid retraction were significant $(p<0.001$, paired $t$-test).

The reduction in the asymmetry of the vertical palpebral aperture following Henderson's procedure (Fig. 4) just failed to reach the $5 \%$ level of significance $(p=0.052)$ using the Wilcoxon matched pairs signed ranks test.

Eight patients (36\%) required further upper eyelid
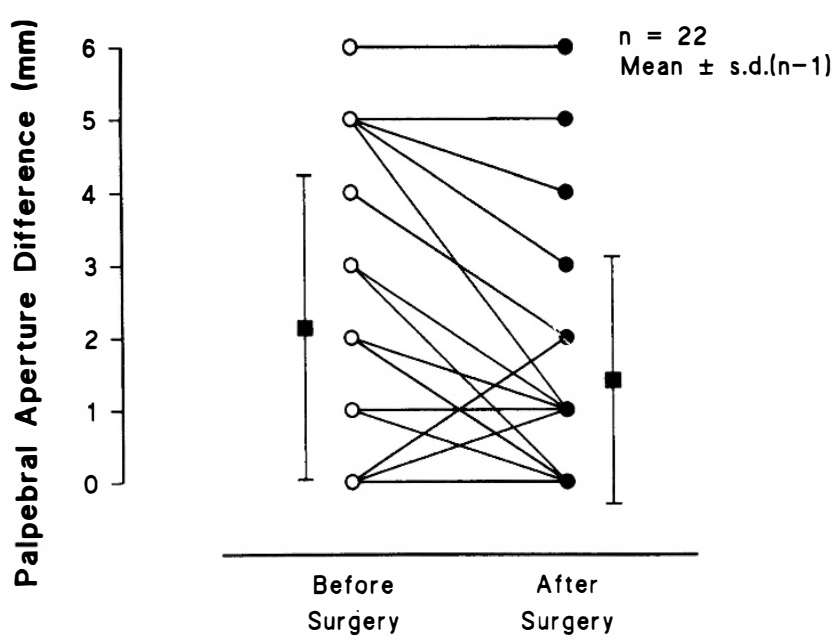

Fig. 4. There was a general reduction in palpebral aperture asymmetry following Henderson's procedure but this was not significant ( $\mathrm{p}=0.052$, Wilcoxon matched pairs signed ranks test).
Table I. Details of further surgery $(n=8 ; 36 \%)$

\begin{tabular}{lc}
\hline Operation & No. of patients \\
\hline Lateral tarsorrhaphy & 2 \\
Bilateral anterior approach levator recession & 1 \\
Bilateral posterior approach levator recession & 2 \\
Bilateral Grove myotomy & 1 \\
Unilateral levator recession adjustable sutures & 2 \\
\hline
\end{tabular}

Table II. Reasons for which further surgery was performed or recommended $(n=11 ; 50 \%)$

\begin{tabular}{lc}
\hline Reason for surgery & No. of patients \\
\hline Persistent upper lid retraction & 9 \\
Contour lateral flare & 4 \\
Asymmetry & 5 \\
\hline
\end{tabular}

surgery (Table I) and three patients (14\%) were recommended to have further surgery but declined for personal reasons. No patient required more than one further operation. The reasons for failure were asymmetry, persistent eyelid retraction and persistent lateral contour flare (Table II). Six of the eight patients who had further surgery originally had unilateral Henderson's procedures for either unilateral upper eyelid retraction or asymmetrical eyelid retraction. One patient who had unilateral Henderson's required subsequent bilateral levator recessions. Three patients had asymmetrical proptosis (3-6 $\mathrm{mm}$ difference), all of whom had a unilateral Henderson's procedure; 2 of the 3 required further surgery because of persistent upper eyelid retraction and lateral flare.

\section{DISCUSSION}

The re-operation rate of $36 \%$ appears high when compared with other series (Table III). This high

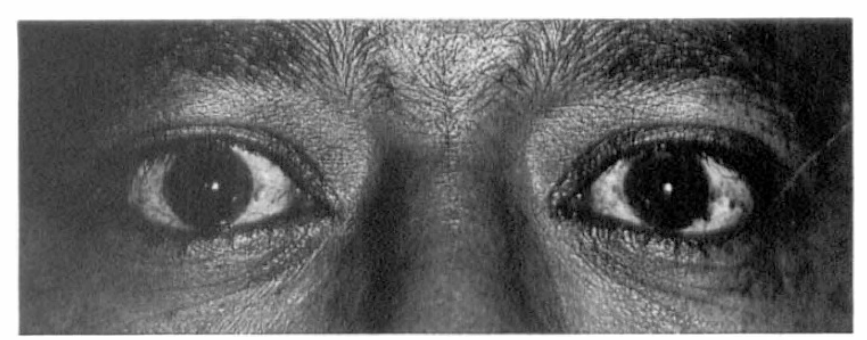

(a)

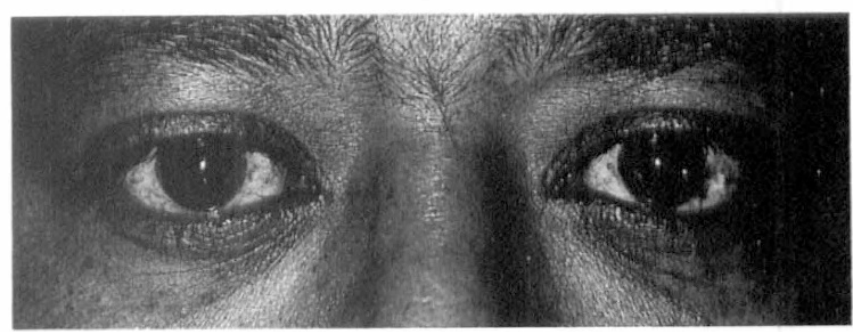

(b)

Fig. 5. Bilateral symmetrical slight upper eye lid retraction. (a) Pre-operative. (b) Six months after bilateral Henderson's procedure. 
Table III. Published results of upper lid retraction surgery in thyroid eye disease

\begin{tabular}{|c|c|c|c|c|}
\hline \multirow[b]{2}{*}{ Author } & \multirow[b]{2}{*}{ Operation } & \multicolumn{3}{|c|}{ Patients re-operated } \\
\hline & & No. & $\%$ & Reason \\
\hline Moran (1956) ${ }^{7}$ & Levator division & $5 / 12$ & 41 & $\begin{array}{c}\text { Contour abnormal; } \\
\text { overcorrection }\end{array}$ \\
\hline Henderson $(1965)^{9}$ & Mullerotomy \pm division of aponeurotic fibres on anterior tarsal plate & $1 / 27$ & 4 & Re-retraction \\
\hline Chalfin and Putterman (1979) ${ }^{12}$ & Mullerectomy \pm levator recession & $5 / 21$ & 24 & $\begin{array}{c}\text { Contour abnormal; } \\
\text { overcorrection }\end{array}$ \\
\hline Grove $(1980)^{15}$ & Levator marginal myotomy & $0 / 4$ & 0 & \\
\hline Doxenas and Dryden $(1981)^{14}$ & Scleral spacer & $3 / 18$ & 16 & Residual retraction \\
\hline Harvey and Anderson $(1981)^{13}$ & Anterior approach mullerectomy and levator recession & $4 / 24$ & 17 & Overcorrection \\
\hline
\end{tabular}

failure rate may be the result of changes in our attitude to thyroid eye disease and represent the increased expectations of patients as to what constitutes an acceptable endpoint for cosmetic surgery in thyroid eye disease. In Henderson's procedure the conjunctiva is left open (without sutures) and therefore there may be an unpredictable degree of upper eyelid re-retraction from subsequent conjunctival shortening.

The indications for surgery for upper eyelid retraction are exposure keratopathy, lagophthalmos and cosmetic. The aims of surgery are therefore corneal protection, external eye comfort and cosmetic. It is usual for the patient to be euthyroid for at least 1 year before undertaking eyelid surgery.

The specific aim of cosmetic surgery is to rehabilitate the thyroid patient to make him or her look 'normal'. Primary orbital decompression ${ }^{2,18}$ has a cosmetic role but also morbidity, including risk of diplopia necessitating subsequent strabismus surgery, and does not negate the need for subsequent eyelid surgery. The surgical aims of upper eyelid retraction surgery are fourfold: (1) to abolish upper scleral show, (2) to produce a normal upper eyelid contour, (3) to maintain a normal skin crease height and (4) to regain or retain symmetry of the vertical palpebral aperture, upper eyelid contour and skin crease.

In this study re-operation was carried out or recommended because of a combination of persistent retraction, persistent lateral flare giving an unsightly lid contour and asymmetry with the other side. We had no overcorrections, consistent with Henderson's findings. ${ }^{9}$ There is, however, a risk of overcorrection with other operations such as mullerectomy and levator recession and with levator marginal myotomy. It is of note that in Henderson's report he describes ${ }^{9}$ performing his procedure at the same time as orbital decompression in 6 of 27 patients, where the effect of decompression alone would have reduced the palpebral apertures.

It is our clinical impression that the upper skin crease rises approximately $1 \mathrm{~mm}$ following Henderson's procedure, but we had inadequate data from which to verify this hypothesis. Henderson ${ }^{9}$ achieved 2-3 mm lowering, a finding borne out in this review, but had only 1 of 27 patients requiring re-operation.
We do not know either the surgeon's indications for re-operation or the patients' level of acceptance of the results. Cosmetic expectations have risen from merely aiming to improve the appearance, to making the patient look 'normal'.

Measurements of upper eyelid retraction based on upper scleral show do in fact underestimate the degree of retraction, as normally the upper eyelid overlies the upper cornea by $1-3 \mathrm{~mm}$. Upper scleral show of $3 \mathrm{~mm}$ may truly be $5 \mathrm{~mm}$ if the eyelid extends $2 \mathrm{~mm}$ over the upper cornea. In addition, measurements of upper scleral show are made in the vertical plane (mid-pupil), with the curve of the upper eyelid not taken into account. Therefore, measurements of change in palpebral aperture are more meaningful than change in upper eyelid retraction.

We found that the disadvantages of the Henderson's procedure were the limited correction achieved, unpredictable outcome and difficulty in correcting contour abnormality such as lateral flare. As a result, the re-operation rate is unacceptably high. Fortunately, re-operation is not difficult since the territory operated on is entirely below the upper skin crease, and most of the aponeurosis and the entire levator muscle are untouched.

Henderson's procedure cannot correct marked lateral contour flare because the surgery is limited to the superior and anterior tarsal plate. Lateral contour flare can only be corrected fully if the adhesions between the shortened levator muscle and the lacrimal gland are divided and the levator muscle recessed more temporally than medially - a procedure which requires more extensive eyelid dissection.

In conclusion, we feel that the procedure should be reserved for only those patients with mild upper eyelid retraction which is either symmetrical or nearly symmetrical, without significant lateral contour flare (Fig. 5).

Key words: Thyroid upper eyelid retraction surgery.

\section{REFERENCES}

1. Frueh BR, Musch DC, Garber FW. Lid retraction and levator aponeurosis defects in Graves' eye disease. Ophthalmic Surg 1986;17:216-20. 
2. Shorr N, Sieff SR. The four stages of surgical rehabilitation of the patient with dysthyroid ophthalmopathy. Ophthalmology 1986;93:476-83.

3. Frueh BR, Garber FW, Musch DC. The effects of Graves' eye disease on levator muscle function. Ophthalmic Surg 1986;17:142-5.

4. Frueh BR, Musch DC, Garber FW. Exopthalmometer readings in patients with Graves' eye disease. Ophthalmic Surg 1986;17:37-40.

5. Schimek RA. Surgical management of ocular complications of Graves' disease. Arch Ophthalmol 1972; 87:655.

6. Goldstein I. Recession of the levator muscle for lagophthalmos in exophthalmic goitre. Arch Ophthalmol 1934;11:389-93.

7. Moran RE. Correction of exophthalmos and levator spasm. Plast Reconstr Surg 1956;18:411-26.

8. Berens C, King JH. Atlas of ophthalmic surgery. Philadelphia: JB Lippincott, 1961: 218.

9. Henderson JW. Relief of eyelid retraction: a surgical procedure. Arch Ophthalmol 1965;74:205-16.

10. Putterman AM, Urist M. Surgical treatment of upper eyelid retraction. Arch Ophthalmol 1972;87:401.
11. Baylis HI, Cies WA, Kamin DF. Correction of upper eyelid retraction. Am J Ophthalmol 1976;82:790.

12. Chalfin J, Putterman AM. Muller's muscle excision and levator recession in retracted upper lid: treatment of thyroid related retraction. Arch Ophthalmol 1979; 97:1487-91.

13. Harvey JT, Anderson RL. The aponeurotic approach to eyelid retraction. Ophthalmology 1981;88:513-24.

14. Doxenas MT, Dryden RM. The use of sclera in the treatment of dysthyroid eyelid retraction. Ophthalmology 1981;88:887-94.

15. Grove AS Jr. Levator lengthening by marginal myotomy. Arch Ophthalmol 1980;98:1433-8.

16. Grove AS. Eyelid retraction treated by levator myotomy. Ophthalmology 1980;87:1013.

17. Collin JRO, O'Donnell BA. Adjustable sutures in eyelid surgery for ptosis and lid retraction. $\mathrm{Br} \mathrm{J}$ Ophthalmol 1994;78:167-74.

18. Lyons CJ, Rootman J. Orbital decompression for disfiguring exophthalmos in thyroid orbitopathy. Ophthalmology 1994;101:223-30. 